\title{
Experiment Study of Loess-filled Embankment under Dynamic Compaction
}

\author{
Yunshan Han*, Yanli Dong, Yuanlong Wang, Wei Duan and Weihua Qin \\ Institute of Civil Engineering, North University of China, Taiyuan, Shanxi, 030051, China
}

\begin{abstract}
To investigate the dynamic compaction mechanism of loess-filled embankment, a computational model of unit volume compaction effort was proposed as compared with the compaction test. The energy level of dynamic compaction used in actual projects was also considered. The differences between the compaction test and the unit volume compaction effort in the actual projects were studied. And also, the unit volume compaction efforts of the main tamping point and the whole reinforcement scope were analyzed. It can be drawn out that the compaction criterion should be chosen based on the water content of loess on site. Based on the model test, the laws of acceleration, velocity and displacement under the dynamic impact of hammer on the loess-filled embankment were analyzed in our study. The whole process also perfectly explained the movement history of hammer under dynamic compaction and the work-energy conversion efficiency of dynamic compaction.
\end{abstract}

Keywords: Compaction effort, dynamic compaction, impact, loess.

\section{INTRODUCTION}

The compaction criterion of dynamic compaction quality control was generally based on the compaction test, the same used at domestic and abroad [1]. The compaction effect of soil was increased linearly with the compaction effort, while the maximum dry density could be affected by the water content. The water content should be controlled nearby the optimum water content [2-4]. In addition, further discussion was needed to determinate the relationship between the compaction coefficient and selection of compaction test [5].

Many papers have been published relating to issues about the process of hammer impacting soil. For example, Jessberger and Beine [6] performed dynamic consolidation test in the lab and obtained that the impact stress was increased linearly with the landing speed according to the Newton's second law. Zhang and Wang [7] believed that dynamic stress was mainly as a single peak with a very short action time and there was no obvious second peak under the dynamic compaction. Feng et al. [8] analyzed the effect of compaction times, falling distance, energy level, hammer diameter, and other parameters on the reinforcement of dynamic compaction. RoIIin and Jorgensen [9] present the empirical relationship between the maximum peak velocity with tamping energy and distance of collapsible loess under dynamic compaction. Some researchers [10-12] used the unit impulse load or finite element method (FEM) to study the impact process under dynamic compaction and reported the results of maximum impact force between hammer and soil, impact duration, tamping displacement, and so on.
From the above references, it is can be known that the inner connection between the compaction effort and compaction test of the whole reinforcement scope should be studied to determine the criterion of dynamic compaction based on the compaction test. For the research of dynamic compaction, most researchers focus on the soil while the hammer and the impact process of hammer. In this study, the model test was adopted to investigate the movement history of hammer and the work-energy conversion efficiency of dynamic compaction. Based on the acceleration versus time history curves obtained from the test, the variation of velocity and displacement of hammer under dynamic compaction was analyzed.

\section{COMPARISON OF UNIT VOLUME COMPAC- TION EFFORT}

\subsection{Unit Volume Compaction Effort of Compaction Test}

The compaction effort of unit volume was used in most countries as the criterion of dynamic compaction. According to the definition of compaction effort:

$\mathrm{E}_{\mathrm{c}}=\mathrm{W} \cdot \mathrm{H} \cdot \mathrm{N} \cdot \mathrm{N}_{\mathrm{L}} / \mathrm{V}$

Ec is compacting effort of the unit volume $(\mathrm{kJ} / \mathrm{m} 3)$;

$\mathrm{W}$ is the weight of hammer $(\mathrm{kN})$;

$\mathrm{H}$ is the falling distance of hammer $(\mathrm{cm})$;

$\mathrm{N}$ is the tamping times per layer;

NL is the layers of filling soil;

$\mathrm{V}$ is the volume of compaction cylinder $(\mathrm{cm} 3)$

At present, two types of compaction and compaction effort of unit volume are listed in Table 1. It is can be known from Table 1 that the unit volume compaction effort of the heavy compaction device is about 4.5 times than the lighter one. 
Table 1. Parameters of compaction test and unit volume compaction effort.

\begin{tabular}{|c|c|c|c|c|c|c|c|c|}
\hline $\begin{array}{c}\text { Test } \\
\text { method }\end{array}$ & $\begin{array}{c}\text { Diameter of hammer } \\
\qquad / \mathbf{m m}\end{array}$ & $\begin{array}{c}\text { Weight of } \\
\text { hammer } \\
\quad / \mathbf{k g}\end{array}$ & $\begin{array}{l}\text { Drop height } \\
\quad / \mathbf{m m}\end{array}$ & \multicolumn{3}{|c|}{ Compaction cylinder } & $\begin{array}{l}\text { Height of casing } \\
\qquad / \mathrm{mm}\end{array}$ & $\begin{array}{c}\text { Unit volume } \\
\text { compaction } \\
\text { effort } \\
/ \mathbf{k J} / \mathbf{m} 3\end{array}$ \\
\hline Light type & 51 & 2.5 & 305 & 102 & 116 & 947.4 & 50 & 604.0 \\
\hline $\begin{array}{l}\text { Heavy } \\
\text { type }\end{array}$ & 51 & 4.5 & 457 & 152 & 116 & 2103.9 & 50 & 2739.7 \\
\hline
\end{tabular}

\subsection{Computational Model of Compaction Effort per unit Volume under Dynamic Compaction}

Reinforcement mechanism of dynamic compaction is similar as compaction test. Thus, the computational model of compaction effort per unit volume under dynamic compaction can be proposed referring to the compaction test. The lateral confinement of soil in the compaction test is rigid because of the compaction cylinder while the lateral confinement is not obvious and the reinforcement volume is hard to decide under dynamic compaction. In this paper, the calculating volume of compaction effect per unit volume of the tamping point under dynamic compaction was defined as product of the area of hammer times the effective reinforcement depth for simplification. The equation of compaction effort per unit volume under dynamic compaction can be given as follows:

$\mathrm{E}_{\mathrm{dc}}=\mathrm{Q} / \mathrm{V}$

Where $\mathrm{Q}$ is the tamping energy, $\mathrm{V}$ is the calculating volume of compaction effect per unit volume of the tamping point under dynamic compaction.

The compaction effects per unit volume of the main tamping point in the actual projects were calculated using Equation 2 and the results are listed in Table 2. The comparison of the calculated compaction effort per unit volume under the tamping point with the one of compaction test listed in Table 1. The results are listed in Table $\mathbf{3}$.

Table 2. Ratios of compaction effect per unit volume.

\begin{tabular}{|c|c|c|}
\hline Number & Edc/E1 & Edc/E2 \\
\hline \hline 1 & 2.98 & 0.66 \\
\hline 2 & 4.42 & 0.97 \\
\hline 3 & 4.97 & 1.10 \\
\hline 4 & 5.42 & 1.19 \\
\hline
\end{tabular}

Table 3 shows that the value of compaction effect per unit volume under dynamic compaction is lager than the one of light compaction test, while the values of several relatively low energy levels could not reach the values of the heavy compaction test.

In real application, the combination method of dynamic compaction was used. Here, the compaction effect per unit volume of dynamic compaction $\mathrm{E}$ 'dc can be expressed as:
$E_{d c}^{\prime}=w / v$

Where $\mathrm{w}$ is compaction energy of the single tamping

point, $\mathrm{v}=\mathrm{S} * \mathrm{~h}$ is reinforcement volume under the tamping point, $\mathrm{s}$ is reinforcement area of the tamping point, $\mathrm{h}$ is effective reinforcement depth under the main tamping point. If the distribution of tamping point distance is equilateral triangle, $\mathrm{s}=0.6495 \mathrm{~d} 2$; if the distribution is square, $\mathrm{s}=\mathrm{d} 2$.

Table 4 shows that at the combination of energy level, all the values of compaction effect per unit volume are larger than the values of light compaction test and did not reach the values of heavy compaction test.

\subsection{Selection of Compaction Criterion}

The curves of heavy and light compaction tests are shown in Fig. (1). According to Table 5, when the water content $\omega$ was close to $\omega 2$ (i.e. the optimum water content of light compaction test), the compaction effect per unit volume under tamping point is not easy to reach the one of heavy compaction test. If the arrangement of the tamping points were adjusted, the maximum dry density and the degree of compaction could only meet the requirements of light compaction test criterion rather than the requirements of heavy one. Thus the light compaction test criterion is more suitable than the heavy one. On the other side, when the water content $\omega$ was close to $\omega 1$ (i.e. the optimum water content of heavy compaction test), we can increase the compaction effect per unit volume under tamping point by adjusting the arrangement of the tamping points to meet the requirements of heavy compaction test. And also, the maximum dry density and the degree of compaction could reach at the same time.

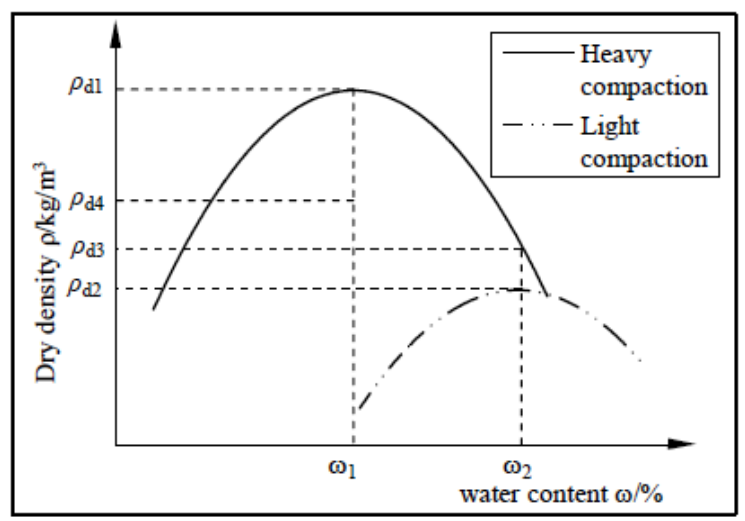

Fig. (1). The compaction curve of light and heavy compaction test with the earth. 
Table 3. Compaction effect per unit volume at different compaction energy level.

\begin{tabular}{|c|c|c|c|c|c|c|c|}
\hline Number & $\begin{array}{c}\text { Compaction } \\
\text { energy } \\
\text { /kN·m }\end{array}$ & $\begin{array}{l}\text { tamping times } \\
\qquad / \mathbf{N}\end{array}$ & $\begin{array}{c}\text { Tamping en- } \\
\text { ergy } \\
/ \mathbf{k N} \cdot \mathbf{m}\end{array}$ & $\begin{array}{c}\text { Bottom area } \\
\text { of hammer } \\
\text { /m2 }\end{array}$ & $\begin{array}{c}\text { Effective rein- } \\
\text { forcement } \\
\text { depth/m }\end{array}$ & $\begin{array}{c}\text { Calculating } \\
\text { volume } \\
/ \mathrm{m3}\end{array}$ & $\begin{array}{c}\text { Compactive } \\
\text { effect per unit } \\
\text { volume } \\
\text { Edc/kJ/m3 }\end{array}$ \\
\hline 1 & 6000 & 12 & 72000 & 5 & 8 & 40 & 1800.0 \\
\hline 3 & 10000 & 15 & 150000 & 5 & 10 & 50 & 3000.0 \\
\hline 4 & 12000 & 15 & 180000 & 5 & 11 & 55 & 3272.7 \\
\hline
\end{tabular}

Table 4. Compaction effect per unit volume at different compaction energy level combination.

\begin{tabular}{|c|c|c|c|c|c|c|c|}
\hline \multirow{2}{*}{1} & Main tamping & 6000 & $5.5 \times 5.5$ & 19.65 & \multirow{2}{*}{8} & 15 & \multirow{2}{*}{743.6} \\
\hline & Vice tamping & 3000 & $4.5 \times 4.5$ & 13.15 & & 6 & \\
\hline 2 & Vice tamping & 4000 & $5.0 \times 5.0$ & 16.24 & 9 & 6 & 848.6 \\
\hline \multirow{2}{*}{3} & Main tamping & 10000 & $6.5 \times 6.5$ & 27.44 & \multirow{2}{*}{10} & 18 & \multirow{2}{*}{1025.4} \\
\hline & Vice tamping & 4000 & $5.0 \times 5.0$ & 16.24 & & 15 & \\
\hline
\end{tabular}

Table 5. Ratios of compaction effect per unit volume (combination of energy level).

\begin{tabular}{|c|c|c|}
\hline Number & $E_{d c}^{\prime} / E_{1}$ & $E_{d c}^{\prime} / E_{2}$ \\
\hline \hline 1 & 1.23 & 0.27 \\
\hline 2 & 1.40 & 0.31 \\
\hline 3 & 1.70 & 0.37 \\
\hline 4 & 2.01 & 0.44 \\
\hline
\end{tabular}

\section{MODEL TEST OF DYNAMIC COMPACTION}

In this study, the weight of the hammer was $39 \mathrm{~kg}$ with a diameter of $32 \mathrm{~cm}$. The falling distance of $2.5 \mathrm{~m}$ was used. Compaction energy of $975 \mathrm{~N} \cdot \mathrm{m}$ was selected in all the tests. The loess was used as the filling soil. The test was terminated when the number of tamping reached 14 strike.The acceleration transducers were fixed on the hammer to collect the signals of dynamic acceleration. Fig. (2) shows the apparatus used in the test.
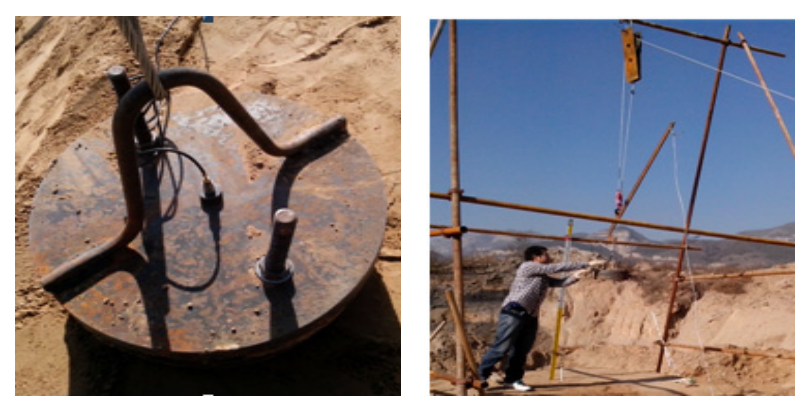

Fig. (2). The apparatus of test equipment.

\section{ANALYSIS OF HAMMER IMPACT PROCESS}

The acceleration versus time history curve at the eighth strike was chosen as illustration. The curves of velocity and displacement are obtained through numerical integral, separately. The curves were presented in Fig. (3) and Fig. (4).

Fig. (3) shows that the acceleration of the hammer increased suddenly in a very short time when reached to the interface of the ground (i.e. position 1) and then reached a maximum value at position 2 . The velocity of hammer was reduced because of the reaction of soil during this process. 


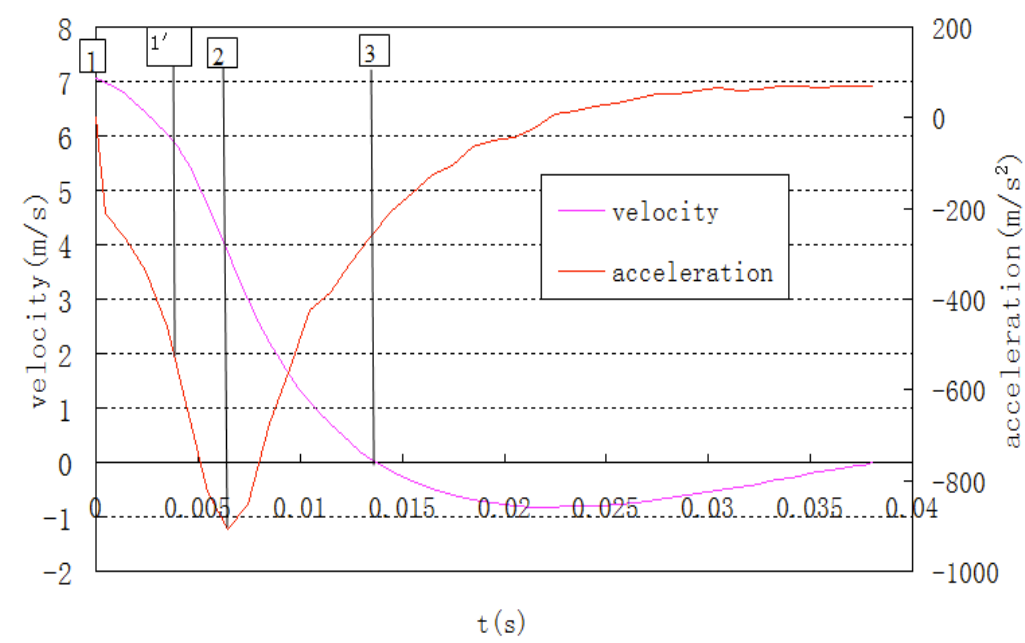

Fig. (3). The curves of acceleration and velocity of hammer versus impact time history under the 8th strike.

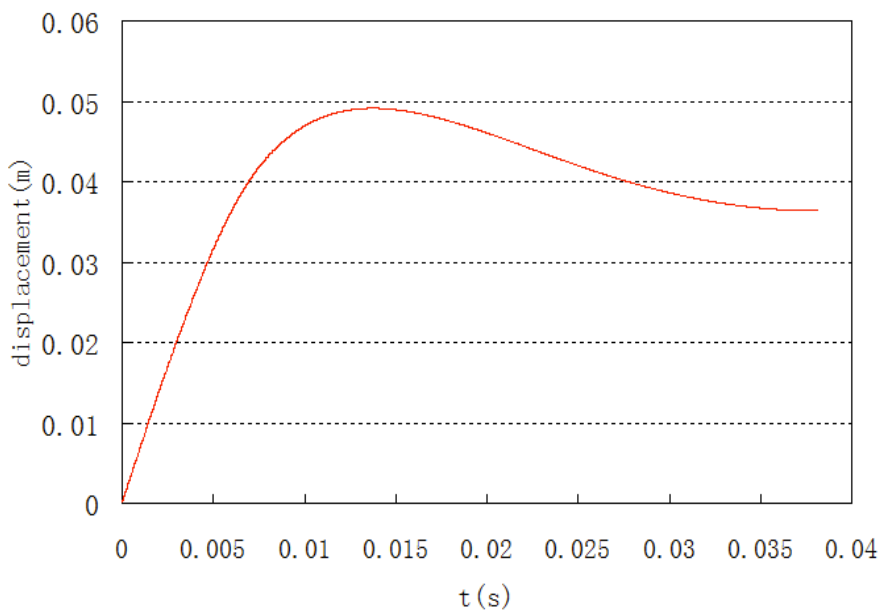

Fig. (4). The curves of displacement of hammer versus time history under the 8th strike.

When the position of hammer reached position 3, the velocity of hammer was reached to zero. At this time, the period of impact was $13.6 \mathrm{~ms}$ larger than the one at position 2 (i.e. $6.4 \mathrm{~ms}$ ). That is to say, the velocity of hammer did not decreased to zero at position 2 when the acceleration of the hammer reaching the maximum value. The compaction process at position 2 did not finished with a velocity of 3.61 $\mathrm{m} / \mathrm{s}$. Actually, the velocity of hammer using another $7.2 \mathrm{~ms}$ to reduced to zero at position 3. At this time, there was no compressing any more. Therefore, the moment of velocity equal to zero lagged behind the moment of acceleration reach to maximum. The two moments did not synchronize which further demonstrates that the compaction process of hammer impact to foundation was not the elastic collision. There was elastic-plastic deformation existed at position 2 .

It was can be predicted that the elastic-plastic deformation appeared after compaction due to the impact effect of hammer. When the acceleration reached the maximum value (i.e. the maximum reaction) at position 2 , there was still elastic-plastic damage existed to produce residual elastic-plastic deformation. The reaction of soil to hammer was no longer increased but decreased. Meanwhile, the acceleration decreased gradually until to the velocity becomes to zero at position 3. The value of acceleration was $258.8 \mathrm{~m} / \mathrm{s}^{2}$ at position 3 still larger than the one of acceleration of gravity. At this moment, the value of reaction was larger than the gravity of hammer and the movement of hammer would become to upward with a duration of $24.4 \mathrm{~ms}$. The actual performance was a little rebound (i.e. the recovery of the elastic deformation) and became to static soon.

From the analysis mentioned above, it was can be known that the $0.009 \mathrm{~m}$ thickness of soil continues to be compressed to position 3 .

Fig. (4) presents that there was a slight rebound of hammer at position 3 which can be approximate considered as elastic rebound of the foundation. The total compression displacement of soil was $0.02 \mathrm{~m}$ which can be calculated by the calculated value of the slight rebound of hammer (i.e. $0.017 \mathrm{~m}$ ) added to the measured settlement of dynamic compaction (i.e. $0.003 \mathrm{~m}$ ). It was can be considered that the real contact moment between the bottom of hammer and the soil was the moment at position $1^{\prime}$, which also was the moment of associated movement. The elastic- plastic deformation of soil appeared at the same time. The duration of the main impact process from position $1^{\prime}$ to position 3 was $9.74 \mathrm{~ms}$ and 
more time of $38.0 \mathrm{~ms}$ was needed until the end of the rebound.

In Fig. (3), it must be pointed out that the acceleration shows an obvious variation before the hammer reached to position $1^{\prime}$, although the hammer was not contact with the soil. The hammer may encounter frictional resistance from the tamping pit side. But the authors believed that the main resistance was because of the air cushion between the bottom of hammer and the surface of tamping pit. The objects such as earth and rock blocks that extruded from the pores of hammer in the practical engineering application also illustrated the existence of air cushion.

Based on the analysis of energy conversion, the potential energy (i.e. $975 \mathrm{~N} \cdot \mathrm{m}$ ) was converted to kinetic energy after the hammer freely falling to the ground. This kinetic energy plus the potential energy generated during the process of the soil compression (named as the tamping potential energy with a value of $0.003 \times 39 \times 10=1.17 \mathrm{~N} \cdot \mathrm{m}$, which apparently could be ignored here) formed the total energy of hammer. During the process of impact, the work (named as ineffective A) to overcome the air cushion and side friction resistance would be done first. And then one part of the work done to destroy and compressed the soil was would be absorbed by the soil system (named as ineffective B, part of which showed as the rebound of soil and hammer). The other part would be converted to the soil plastic energy (named as effective C).

The work of hammer could be calculated through the numerical integration. The calculated work of hammer done to overcome the resistances from position 1 to position 3 was 973.27 N.m, very close to the total energy of $976.17 \mathrm{~N}$.m. The results and its accuracy confirmed validity of the idea and the numerical integration method. The ineffective work A done by the hammer from position 1 to position 1 ' was 380.13 N.m. The work done by the hammer from position 1 ' to position 3 was the sum of the ineffective work B and effective work C. Because of the simultaneity of elastic deformation and plastic deformation of soil and hard to distinguish, we assumed the elastic deformation was $0.017 \mathrm{~m}$ and the plastic deformation was $0.003 \mathrm{~m}$ in this paper. Thus, the calculated work of hammer was $538.16 \mathrm{~N} \cdot \mathrm{m}$ and $54.98 \mathrm{~N} \cdot \mathrm{m}$, separately.

The efficiency dynamic compaction was defined as the ratio of the effective work $\mathrm{C}$ to the total work done during the process of the hammer reach to position 3 :

$$
\eta=\frac{\text { effective work }}{\text { total work }}=\frac{54.98}{973.27}=5.65 \%
$$

Where the percentage of the ineffective work A done to overcome the air cushion and side friction resistance could be expressed as:

$$
\frac{380.13}{973.27}=39.06 \%
$$

The percentage of the absorbed and dissipated ineffective work B could be expressed as:

$$
\frac{538.16}{973.27}=55.29 \%
$$

It was can be drawn out that, in order to improve the dynamic compaction efficiency, the proportion of ineffective work should be reduced first. Especially, the reduction of air cushion effect before the hammer contact with soil should be paid more attention for our researchers. This issue relates to the hammer shape especially the improvement of the bottom shape of hammer and the design of the vent hole. In addition, the combinations between the weight of hammer and the falling distance had important factors effect on air cushion effect. While the ineffective work B caused by the system characteristics of soil was affected by arrangement of tamping points and degree of reinforcement its surrounding soil. Further researches are needed to be done in the following work.

\section{CONCLUSION}

Referred to the compaction test, two computational models of compaction effect per unit volume under dynamic compaction were proposed in this paper. The calculated compaction effects per unit volume were compared with the ones of light and heavy compaction test. It was can be drawn out that the criterion of light compaction test was more suitable when the in-situ water content of filling soil close to of the optimum water content of light compaction test. While the criterion of heavy compaction test should be selected to reduce the risk of the project when the in-situ water content close to of the optimum water content of heavy compaction test.

Based on the data of model test, the variation laws of acceleration, velocity and displacement of hammer of loessfilled embankment under dynamic compaction were analyzed. The impact of dynamic compaction has the characteristic of pulse load. The duration of main impact compression was only about $10 \mathrm{~ms}$, a very short time. After the hammer impact and compressed soil, the acceleration reached the maximum value while velocity is not reduced to zero. The elastic-plastic deformation continues to be appeared. The process of compression ends with the velocity reduced to zero. Then the whole impact process of hammer terminated after slight rebound became to stable.

Based on the acceleration versus time history curve, the velocity and displacement of hammer versus time history curves could be obtained by numerical integral. The impact process of hammer during dynamic compaction could be analyzed based on the theory of dynamic mechanics. The factors had effects on energy conversion and efficiency of dynamic compaction and were investigated.

\section{CONFLICT OF INTEREST}

The authors confirm that this article content has no conflicts of interest.

\section{ACKNOWLEDGEMENTS}

This work is supported by the project of National Natural Science Fund for the Youth, China (No.51208473), the Key project for Science and Technology of Shanxi, China (No.20130313010-3), and the project of Natural Science Fund of Shanxi for the Youth, China (No.2012021019-1). 


\section{REFERENCES}

[1] C.G. Shi, "Study of the compaction test standard," Journal of Shi Jia Zhuang Railway Institute," vol. 4,pp.127-133, 1991.

[2] M. Wang, and P. Cao, "Experimental research on engineering mechanics property of dynamic compaction loess," Journal of Water Resources and Architectural Engineering, vol. 6, pp. 29-31, 2008.

[3] Q. Wang, Q. Zhang, Y. F. Ma, Y. Gao, and S.C. Bao, "The influence factors of compaction characteristics and mechanism analysis of laterite in guangxi," Journal of Jilin University (Earth Science Edition), vol. 44, pp. 1960-1965, 2014

[4] M. Jesmanai, and A. N. Manesh, " Optimum water content and maximum dry unit weight of clayey gravels at different comp active effortsElectronic," Journal of Geotechnical Engineering, vol. 13, pp. 1-14, 2008.

[5] Q. Zhang, L.M. Gou, and L. Li, "Discussion on problems of quality inspection of the compacted fill ground," Geotechnical Investigation \& Surveying, vol. 6, pp. 35-37, 2001.

[6] H.L. Jessberger, and R. A. Beine, "Heavy tamping: theoretical and practical aspects," Proceedings of $10^{\text {th }}$ International Conference on Soil Mechanics and Foundation Engineering, pp. 695- 699, 1981.
[7] Q.F. Zhang, and D.Q. Wang, "Model tests on dynamic stress in colliery wastes improved by dynamic compaction," Chinese Journal of Rock Mechanics and Engineering, vol. 6, pp.1142-1147, 2012.

[8] S. J. Feng, H.U. Bin, X. Zhang, and W.H. Shui, "Model test study on impact parameters influence on tamping effect," Journal of Tongji University: Natural Science, vol. 8, pp.1147-1153, 2012.

[9] K.M. Rollins, and S. J. Jorgensen, "Optimum moisture content for dynamic compaction of coiiapsibie soiis," Journal of Geotechnicai and Geoenvironmentai Engineering, vol. 8, pp. 699-708, 1998.

[10] X.G. Song, Y.Y. Li, and J. Han, "Multi-coupling analysis of dynamic consolidation method for reinforcing foundations," Rock and Soil Mechanics, vol. 3, pp. 471-474, 2003.

[11] X. D. Tong, Y.S. Jiang, W. M. Gong, and S. S. Lu, "A new method for dynamic contact analysis," Engineering Mechanics, vol.6, pp. $82-86,2000$.

[12] S. Tian, and Z. Wang, "Effect of impact mode on treatment effect of dynamic compaction," Rock and Soil Mechanics, vol. 11 pp. 3 119-3123, 2008.

Received: January 19, 2015

Revised: April 17, 2015

Accepted: May 18, 2015

(C) Han et al.; Licensee Bentham Open.

This is an open access article licensed under the terms of the (https://creativecommons.org/licenses/by/4.0/legalcode), which permits unrestricted, noncommercial use, distribution and reproduction in any medium, provided the work is properly cited. 